
\title{
R Research S Surare \\ Perinatal caprine milk oligosaccharides consumption alters maternal and offspring liver gene expression
}

Caroline Thum ( $\nabla$ caroline.thum@agresearch.co.nz )

Agresearch Grasslands Research Centre https://orcid.org/0000-0002-9823-1012

Wayne Young

AgResearch Ltd Grasslands Research Centre

Nicole C Roy

Riddet Institute, Massey University

Warren C McNabb

Riddet Institute, Massey University

\section{Research}

Keywords: Caprine milk oligosaccharides, perinatal, liver, microarray, lipid metabolism, visceral fat

Posted Date: January 2nd, 2020

DOI: https://doi.org/10.21203/rs.2.19832/v1

License: @ (i) This work is licensed under a Creative Commons Attribution 4.0 International License.

Read Full License 


\section{Abstract}

Consumption of caprine milk oligosaccharides (CMO) by dams during gestation and lactation, compared to a control diet or a diet supplemented with galacto-oligosaccharides (GOS), was associated with decreased maternal liver weight, increased offspring body weight and length at weaning, and increased offspring visceral fat and serum leptin concentration 30 days after weaning. These changes suggest that dietary $\mathrm{CMO}$ alters lipid metabolism, both in dams and offspring. We hypothesized that perinatal CMO intake affected expression of maternal genes in the liver involved in energy metabolism, and programmed pups' metabolic function leading to increased post-weaning visceral adiposity. To characterise the effects of perinatal consumption of CMOs on maternal and offspring liver gene expression, C57BL/ 6 mice were fed either a control, CMO, or GOS diet from mating to weaning. From weaning, half of the pups from each maternal group were fed the control diet for 30 days. Microarray analysis was conducted on liver samples from dams and offspring. Differences in the expression of genes involved in lipid metabolism were observed in dams and changes in expression of hepatic genes involved in energy balance and steroid metabolism were observed in pups at weaning. Increased visceral fat was observed in pups 30 days. Perinatal consumption of $\mathrm{CMO}$ diet affected infant lipid metabolism, which may be related to altered expression of genes in the liver involved in energy balance and lipid metabolism in dams.

\section{Introduction}

Maternal diet during pregnancy can affect both maternal health, and short and long-term health outcomes in the offspring (1). Human and rodent studies have shown that supplementing the maternal diet with prebiotics can improve maternal gut microbiota and offspring development by increasing weight gain, colon length, muscle and bone mass, and decreasing the incidence of allergies and asthma symptoms (2-5).

Caprine milk oligosaccharides (CMO) were shown to support the growth of gut beneficial bacteria in vitro studies $(6,7)$ revealing $\mathrm{CMO}$ had potentially had prebiotic effects. Using a mouse model, the consumption of $\mathrm{CMO}$ by dams during gestation and lactation, compared to the consumption of a control diet or diet supplemented with galacto-oligosaccharides (GOS), was associated with changes in the maternal colon microbiota, and in milk composition, which affected pup development (8). The specific findings related to $\mathrm{CMO}$ consumption by dams included (i) increased milk protein concentration; (ii) decreased liver weight in dams; (iii) increased colon length in dams and pups at weaning; (iv) increased body weight and length and proportions of Bifidobacterium in the colon of pups at weaning; and iv) increased body visceral fat and serum leptin concentration in pups 30 days after weaning. These findings highlight the potential for indirect effects of food components in the maternal diet on offspring development, gastrointestinal tract (GIT) composition, and metabolism.

Changes in colon microbiota and increased body fat and serum leptin concentration observed in dams and pups after maternal consumption of $\mathrm{CMO}$ may indicate that $\mathrm{CMO}$ altered lipid metabolism, both in dams and offspring. For example, the $\mathrm{CMO}$ diet modified dams' colon microbiota by increasing the 
concentrations of the genera Oscillibacter spp. and Odoribacter spp. compared to dams fed GOS and control diets (8). Recent data suggest that the abundance of Oscillibacter $\operatorname{spp}(9,10)$ and Odoribacter spp (11) are increased in obese individuals and correlate with decreased intestinal barrier function. Although no difference was found in dams' body weight or visceral fat, a decrease in liver weight may indicate decreased fat accumulation in this organ (12) and/or altered lipid metabolism (13). Altered lipid metabolism could also be observed in pups 30 days after weaning, which had an increase in visceral body fat and leptin serum concentration compared to pups from dams fed GOS or a control diet (8).

Rodent studies indicate that the consumption of prebiotics (e.g. inulin, oligofructose) has beneficial effects on lipid metabolism by positively altering an individual's serum lipid profile and decreasing hepatic steatosis (14). However, effects of perinatal prebiotic intake on the programming of offspring lipid metabolism have not been well established. We have previously reported the effects of $\mathrm{CMO}$ on liver adiposity and the gut microbiome (8). Here we describe liver gene expression in samples from the same study.

The hypothesis of this study was that perinatal $\mathrm{CMO}$ intake affected maternal liver genes involved in energy metabolism and programmed pups' metabolic function leading to increased post-weaning visceral adiposity. Therefore, the aim of this study was to determine the effects of perinatal consumption of CMO, GOS or a control diet on maternal and offspring liver gene expression.

\section{Material And Methods}

\subsection{Animals and study design}

As previously described (8), animal experimentation was approved by AgResearch Grasslands Animal Ethics Committee (Application No. AE12579), in accordance with the New Zealand Animal Welfare Act 1999, New Zealand. Sixty-three C57BL/ 6 mice (42 female and 21 male) were obtained from the AgResearch Ruakura Small Animal Facility, Hamilton, New Zealand and housed in a temperature and a humidity-controlled facility with a 12-h light/dark cycle. After acclimatization, 9-week-old mice were randomly assigned to groups of two females and one male and fed one of the following diets; AIN-76A (control diet), AIN-76A supplemented with $1 \%$ GOS (GOS diet), or AIN-76A supplemented with caprine milk oligosaccharide fraction (CMOF) containing 1\% caprine milk oligosaccharides (CMO diet). Diets were formulated by Research Diets, Inc. (NJ, USA). The CMO diet also contained $0.2 \%$ of GOS and other sugars as a result of the method used to obtain the CMOF (Table 1). To ruled out the effect of GOS on maternal and offspring health outcomes $1 \%$ GOS was supplemented to the control diet.

CMOF was obtained by a previously described method (15). In short, caprine milk whey was processed by a combination of ultrafiltration, enzymatic hydrolysis of lactose, solid-phase extraction, and rotary vacuum evaporation. Oligosaccharide characterization and quantification were performed on a Thermo Scientific LTQ XL-Linear Ion TrapMass Spectrometer (Thermo Fisher Scientific, Waltham, MA, USA) with electrospray ionization in negative mode using appropriated standards. Other sugars (lactose, galactose 
and glucose) were characterized and quantified using high-performance liquid chromatography connected to a ThermoHypercarb column (Thermo Fisher).

Mice were mated, and stablished pregnancy was evaluated by the presence of a vaginal plug. After delivery, pups remained with their dams up to weaning ( 21 days) where dams and half of the pups were euthanized by $\mathrm{CO}_{2}$ and cervical dislocation and sampled. To determine the longer-term effects of maternal diet, the remaining pups were fed the control diet for 30 days, then euthanized. The left lobe of liver was collected from each animal and kept at $-80^{\circ} \mathrm{C}$ until analysis. Complete experimental methods and results were previously described in Thum, et al (2016) (8).

\subsection{Liver RNA extraction}

Gene expression profiles in the liver samples ( $\mathrm{n}=4$ animals per treatment per age group) was measured using Agilent Mouse Gene Expression 8x60K microarrays (catalog number G4852A; Agilent Technologies, California, USA), with each array consisting of 60,000 sequence probes, which map to 39,430 unique Entrez Gene identifiers, and 32974 unique gene symbols (16).

RNA and protein were extracted from liver tissue using the Qiagen AllPrep DNA/RNA/Protein Mini Kit according to the manufacturer's instructions (Qiagen Inc., California, USA). The RNA integrity was assessed using a RNA6000 Nano Labchip kit with an Agilent 2100 Bioanalyzer (Agilent Technologies), and only RNA samples with an RNA Integrity Number (RIN) greater than 6 used for subsequent analysis.

Extracted sample RNA and reference RNA were transcribed into cRNA and simultaneously labelled with cyanine dyes Cy3 or Cy5 according to the two-colour Quick Amp Labelling kit (Agilent Technologies). RNA that met quality criteria was transcribed into complementary RNA (CRNA) using T7 RNA polymerase and simultaneously amplified and labelled with the green fluorescent dye Cy3 or red fluorescent dye Cy5, in a dye-swap design, to avoid dye bias effect. The reference RNA used was extracted from intestine, kidney, liver and foetus of Swiss mice. The quality of the amplification and incorporation of the dye were assessed using a NanoDrop ND-1000 spectrophotometer, and only samples with a cRNA yield greater than $825 \mathrm{ng}$ and a specific activity greater than 8 pmol Cy3 or Cy 5 per $\mu \mathrm{g}$ cRNA were used. RNA Spike-in kits were included as instructed by the manufacturer (Agilent Technologies, California, USA).

Samples were hybridised onto Agilent Mouse Gene Expression 8x60K microarrays using four biological replicates per treatment/age, with 1 hybridisation for each biological replicate. Gene expression hybridisation kits were used as instructed. Microarray slides were placed in a hybridisation oven set to $65^{\circ} \mathrm{C}$ and $10 \mathrm{rpm}$ for $17 \mathrm{~h}$. Thereafter, slides were washed in Wash Buffer 1 and 2 (Agilent Technologies), acetonitrile, and Stabilisation and Drying solution (Agilent Technologies). Immediately after washing, slides were scanned at $5 \mu \mathrm{m}$ resolution using an Agilent Technologies Scanner G2505B with feature extraction software (version 10.10.1.1) to extract the raw microarray images.

\subsection{Microarray data analysis}


Microarray data were processed using the Bioconductor suite of packages in R (17). Differentially expressed genes were determined using an empirical Bayes modified t-statistic with the limma package (18). Genes with a $>1.5$-fold-change (FC) and a Benjamini and Hochberg false-discovery rate adjusted Pvalue (q) $<0.05$ were considered to be differentially expressed. Gene Ontology functions of the differentially expressed mapped genes were identified using the GeneMANIA (19) plugin for Cytoscape (20) using default settings. Additionally, gene set enrichment analysis (GSEA) was performed using the limma package in $\mathrm{R}$ on pathways listed in the Reactome curated database (21)

(http://www.reactome.org/), with $\mathrm{P}<0.05$ considered significant. It is important to note that, although validation of microarray data by $\mathrm{QPCR}$ is widely thought to be required, the reliability of using one technology to confirm the results of the other presents its own limitations. Nevertheless, it has been repeatedly demonstrated that the two methods yield comparable results, making repeated validation unnecessary. Furthermore, qPCR cannot be used to assess or confirm results from methods such as GSEA, which examine pathway-wide transcriptional changes.

\section{Results}

Dams fed the CMO, or GOS diet had 119 and 133 differentially expressed unique genes in the liver, respectively, compared to dams fed the control diet (Figure 1). The effects of maternal diet were also observed in the pups liver gene transcription where pups at weaning from dams fed CMO and GOS had 109 and 85 genes differently expressed, respectively. The longer-term effects of maternal diets were less prominent in pups; after they consumed the control diet for 30 days, only 7 and 2 liver genes were differently expressed in pups from dams fed the CMO and GOS diet, respectively (Figure 1).

We have previously shown that perinatal CMO intake did not affect maternal food intake nor body or visceral fat weight but lower liver weight (control, $85.8 \pm 2.6$; GOS, 86.0 \pm 2.9 ; CMO, $73.1 \pm 3.8$; mean $[\mathrm{mg} / \mathrm{g}] \pm \mathrm{SE} ; \mathrm{p}$-value $=0.05)$ compared to control fed dams (8). Here we show that differentially expressed genes in dams fed the CMO diet compared to dams fed the control diet (Table 2, Supplementary material Figure 1) were primarily involved in the regulation of lipid metabolism or ubiquitination and SUMOylation (addition of a small ubiquitin-like modifier).

At weaning, pups from dams fed the CMO diet had increased body weight (control, $4.69 \pm 0.1 ; \mathrm{GOS}, 4.98$ $\pm 0.1 ; \mathrm{CMO}, 5.20 \pm 0.09 ;$ mean $[\mathrm{mg} / \mathrm{g}] \pm \mathrm{SE} ; \mathrm{p}$-value $=0.02$ ) and length (control, $5.17 \pm 0.06 ; \mathrm{GOS}, 5.35 \pm$ 0.06 ; CMO $5.38 \pm 0.04 ;$ mean $[\mathrm{mm} / \mathrm{g}] \pm \mathrm{SE} ; \mathrm{p}$-value $=0.04$ ) compared to pups from dams fed the control diet, as previously reported (8). Genes involved in the regulation of mitochondrial membrane permeability in apoptotic processes, cytochrome P450 activity, and steroid metabolism were differentially expressed in the liver of pups from dams fed CMO compared to pups from dams fed the control diet (Table 3, Supplementary material Figure 2).

After thirty days of receiving the control diet, pups from dams fed the CMO diet had increased visceral fat weight (control, $46.2 \pm 1.7$; GOS, $52.2 \pm 2.5 ; \mathrm{CMO}, 55.9 \pm 2.8$; mean $[\mathrm{mg} / \mathrm{g}] \pm \mathrm{SE}$; $\mathrm{p}$-value $=0.05$ ) and serum leptin (control,7.1 $\pm 0.8 ; \mathrm{GOS}, 9.5 \pm 0.9 ; \mathrm{CMO}, 10.4 \pm 1.2 ; \mathrm{ng} / \mathrm{mL}$, mean $\pm \mathrm{SE} ; \mathrm{p}=0.05$ ) compared to pups 
from dams fed the control diet (8). By thirty days after weaning only a small number of liver genes were differentially expressed in pups from dams fed $\mathrm{CMO}$ compared to pups from dams fed the control diet (Table 4, Supplementary material Figure 3), so Gene Ontology analysis using GeneMANIA was not possible. However, analysis of the pups' liver transcriptome by GSEA indicated other pathways were also affected by maternal diet in pups 30 days after weaning (Table 5). The expression of genes involved in the synthesis of epoxy (EET) and dihydroxyeicosatrienoic acids (DHET) was increased by $25 \%$. Genes involved in collagen metabolism such as assembly of collagen fibrils (11\%), collagen degradation (6\%), collagen biosynthesis (6\%) and formation (7\%), and genes involved in extracellular matrix proteoglycans (6\%) were down-regulated in pups 30 after weaning from dams fed the CMO diet compared to pups from dams fed the control diet (Table 5).

\section{Discussion}

\subsection{Effect of $\mathrm{CMO}$ diet on maternal liver gene expression}

This study showed that perinatal $\mathrm{CMO}$ intake affected expression of genes in the maternal liver related to energy and lipid metabolism compared to the control diet; changes included down-regulatation of genes such as Lcn2 (lipocalin 2) and Prkag1 (protein kinase AMP-activated non-catalytic subunit gamma). Reduction of Lcn2 (7.1 fold) and Prkag1 (1.5 fold), a subunit of 5' AMP-activated protein kinase, has been linked to inhibition of hepatic fatty acid oxidation and promotion of cholesterol synthesis, lipogenesis, and triglyceride synthesis $(22,23)$. Concentrations of lipids and other metabolites, however, were not confirmed by metabolomic or histological analysis of the liver.

When the concentration of hepatic lipids increases, the formation of very low-density lipoprotein (VLDL) particles is stimulated for packaging and circulation of triglycerides, reducing lipid accumulation in the liver (24). Indeed, up-regulation of Apob gene expression ( 2.2 fold) was observed in the dams' liver; this gene provides instructions for making two versions of the apolipoprotein B protein, apolipoprotein B-48 and apolipoprotein B-100. Concentration of blood lipids, however, were not evaluated in this study. The time at which the dams' livers were sampled (weaning) could also affect Apob gene expression, as increased plasma triglyceride and apoB-48 concentrations in dams at weaning have been observed in rats (25). Creb1 (cAMP-response element-binding protein), another up-regulated (1.6-fold) gene in dams fed $\mathrm{CMO}$, has been shown to activate gluconeogenesis and fatty acid oxidation through increased expression of the nuclear hormone receptor peroxisome proliferator activated receptor gamma (PPAR-ү). However, PPAR-y expression was not changed in the liver of dams fed the CMO diet (26).

Genes involved in ubiquitination and SUMOylation were also among differentially expressed transcripts in the liver of dams fed CMO compared to the control diet (Table 2). Post-translational modification of target protein substrates by ubiquitin-like proteins (Ubls) and SUMO proteins regulates cellular signalling in numerous processes such as metabolism, transcription, translation, vesicle transport and apoptosis. Ubiquitination involves at least three classes of enzymes: ubiquitin-activating enzymes, or E1s, ubiquitinconjugating enzymes, or E2s, and ubiquitin-protein ligases, or E3s (27). The genes Ube2h, Ube2d3 and 
Ube2e3, expression of which was higher in dams fed $\mathrm{CMO}$, encode members of the E2 ubiquitinconjugating enzyme family, while Mul1 (mitochondrial ubiquitin protein ligase 1), Rnf220 (ring finger protein 220), Rnf111 and Trim56 (Tripartite Motif Containing 56) genes encode for E3 ubiquitin ligases (Table 2). E3 ubiquitin ligases accept ubiquitin from an E2 ubiquitin-conjugating enzyme in the form of a thioester and then directly transfer the ubiquitin to targeted substrates. Among the different targets of E3 Ubs, Mul1 has been shown to play a role in the control of mitochondrial morphology and to have antiapoptotic activity while Trim 56, and both Rnf111 and Rnf220, promote expression of a type I interferon IFN-beta in response to pathogens and enhance class I MHC mediated antigen processing and presentation. The expression of the SUMO specific peptidase 6 (Semp6) gene was increased in the liver of dams fed CMO compared to those fed the control diet; Senp6 regulates genome stability, cell division, autoimmune responses and ageing (28).

Diet effects on the liver ubiquitome and its role in the regulation of whole-body euglycemia and lipidemia have recently been reported in rats (29). More specifically, it was observed that ubiquitination of proteins is a key regulatory mechanism controlling fatty acid metabolism which may mediate the pathogenesis of fatty acid-associated diseases. Variations observed in this study on liver ubiquitination genes and genes involved in lipid metabolism combined with reduced liver weight suggest that CMO may have modified liver lipid metabolism towards increased energy absorption and utilization.

\subsection{Effects of perinatal $\mathrm{CMO}$ consumption on offspring liver gene expression}

In contrast to our hypothesis, the effects of perinatal diet on pups metabolic function at weaning may have led towards energy expenditure and not accumulation. However, it is also important to note that changes observed in pups liver gene expression at weaning may also be influenced by maternal diet, as pups close to weaning may consume small amounts of maternal diet that may fall into the cage. Pups from dams fed the CMO diet, for example, had increased expression of two genes involved in steroid metabolism at weaning. The expression of both $\mathrm{Hsd} 3 \mathrm{~b} 5$ (3 beta-hydroxysteroid dehydrogenase type 5) and Srd5a1 (3-oxo-5a-steroid 4-dehydrogenase 1) has been shown to negatively correlate with lipid accumulation in liver $(30,31)$. Although no changes in liver weight and other markers for liver lipid metabolism were found at weaning in pups from dams fed CMO, increased body growth (weight and length) may be correlated with changes in gene expression observed in the liver. Concentration of blood lipids, however, were not evaluated in this study.

Modulation of mitochondrial mass is also a major adaptive response to changes in energy balance, arising from decreases in oxygen or glucose availability, among other nutrient stresses (32). However, the effects of a maternal $\mathrm{CMO}$ diet on mitochondrial metabolism were not consistent, as the two proapoptotic genes differentially expressed in pups, Bcl-2 nineteen-kilo dalton interacting protein 3 (Bnip3) and $\mathrm{Bcl}-2$-binding component 3 ( $B b c 3)$, were down-regulated and up-regulated respectively.

Other genes up-regulated in weaned pups from $\mathrm{CMO}-$ fed dams included those related to cytochrome P450s (CYP450) function. CYP450 monooxygenases are capable of catalyzing the metabolism of various endogenous and exogenous compounds, such as bile acids, fatty acids, retinoids, steroids, drugs 
and other xenobiotics. The effects of diet on CYP450 have been established and reviewed (33). An increase in protein-to-carbohydrate ratio in the diet, for example, was shown to increase products of steroid hormone metabolism contributing to the transcriptional regulation of drug-metabolizing genes P450s (34). Indeed, weaned pups from dams fed the CMO diet had increased intake of protein-tocarbohydrate ratio, as maternal milk had higher concentrations of protein compared to control fed dams (8).

By thirty days after weaning, pups from dams fed $\mathrm{CMO}$ compared to control diet, had no indication of expected changes in liver functionality, previously linked with increased visceral fat weight and serum leptin concentration (35). Analysis of the pups' liver transcriptome by GSEA, however, showed that the expression of genes involved in the synthesis of epoxy (EET) and dihydroxyeicosatrienoic acids (DHET) and collagen metabolism were increased.

The EETs are signalling molecules formed within various types of cells by the metabolism of arachidonic acid by a specific subset of CYP450 enzymes. The EETs have been most studied in animal models where they show the ability to prevent arterial occlusive diseases such as heart attacks and brain strokes by their anti-hypertensive and anti-inflammatory effects on blood vessels (36). In the liver, collagens and proteoglycans play an intrinsic role in liver function in health and disease (37). The interaction of collagens and proteoglycans provide architectural elements for the liver with basement membrane or other duct architecture. They have mechanical roles like providing tensile strength and resilience, modulating diffusion and vascular flow, and regulating cell movement (37). Collagens and proteoglycans can also regulate signalling molecules such as growth factors, serving as ligands, storage depots and receptors, via multiple complex interactions between matrix proteins with other signal molecules or among different matrix components (38). However collagen deposition was not evaluated histologically in our study.

Traditionally, visceral obesity is strongly associated with insulin resistance, hypertension, dyslipidemia and systemic chronic low-grade inflammation, all of which play a pivotal role in the pathogenesis of atherosclerosis, thus increasing the risk of cardiovascular disease (39). However, as observed here, no expected changes on liver metabolism linked to the onset of metabolic diseases were observed in pups 30 days after weaning. This may be due to non-pathological residual effects of metabolic changes observed in early life or may be explained by mouse strain variations in response to diet-induced obesity (40).

\section{Conclusions}

Perinatal consumption of the $\mathrm{CMO}$ diet affected maternal and offspring liver gene expression, with effects most prominent in dams (119 genes) and pups at weaning (109 genes) compared to pups 30 days after weaning, which had consumed the control diet (7 genes). Differences in expression of ubiquitination and lipid metabolism-related genes in the dams' liver combined with previously reported reductions in liver weight and changes in colon microbiota (previously reported (8)) of the dams suggest 
that CMO may have modified maternal lipid metabolism towards increased energy absorption and utilization. These effects may have been manifested in the offspring resulting in increased body growth (body length and weight) as well as increasing the expression of genes involved in energy balance and steroid metabolism. The previously reported increase in visceral fat mass, observed post-weaning, is unlikely to be explained by changes in pups liver gene expression (which were minimal), but instead could be a residual effect of metabolic changes observed in dams and pups at weaning trigged by maternal $\mathrm{CMO}$ intake. It is imporntant to notice, there is not necessarily a straightforward correlation between gene expression and protein expression, protein activity (enzyme) and ultimalety, metabolite(s) production by the liver. To deeper understanding of the effects of $\mathrm{CMO}$ on maternal and offspring energy metabolism, more studies are are needed linking gene expression, metabolomic data and liver histology.

\section{Declarations}

Ethics approval

Animal experimentation was approved by AgResearch Grasslands Animal Ethics Committee (Application No. AE12579), in accordance with the New Zealand Animal Welfare Act 1999, New Zealand.

Consent for publication

Not applicable

Availability of data and materials

The datasets used and/or analysed during the current study are available from the corresponding author on reasonable request.

Competing interests

The authors declare that they have no competing interests

Funding

This research was supported by the Riddet Institute, a New Zealand Centre of Research Excellence and the Strategic Science Investment Fund (SSIF) from New Zealand Ministry of Business, Innovation and Employment.

Author's contributions

C.T., N.R., and W.M. designed the study. C.T. supported by W.Y. performed the experiment, analyzed the data, and wrote the paper. All authors proof-read the paper.

Acknowledgements

Not applicable 


\section{References}

1. Lowensohn RI, Stadler DD, Naze C. Current concepts of maternal nutrition. Obstet Gynecol Surv. 2016;71(7):413.

2. Fujiwara R, Takemura N, Watanabe J, Sonoyama K. Maternal consumption of fructo-oligosaccharide diminishes the severity of skin inflammation in offspring of $\mathrm{NC} / \mathrm{Nga}$ mice. $\mathrm{Br} \mathrm{J}$ Nutr. 2010;103(4):530-8.

3. Shadid R, Haarman M, Knol J, Theis W, Beermann C, Rjosk-Dendorfer D, et al. Effects of galactooligosaccharide and long-chain fructooligosaccharide supplementation during pregnancy on maternal and neonatal microbiota and immunity-a randomized, double-blind, placebo-controlled study. Am J Clin Nutr. 2007;86(5):1426-37.

4. Hogenkamp A, Knippels LM, Garssen J, van Esch BC. Supplementation of Mice with Specific Nondigestible Oligosaccharides during Pregnancy or Lactation Leads to Diminished Sensitization and Allergy in the Female Offspring-3. The Journal of nutrition. 2015;145(5):996-1002.

5. Bueno-Vargas P, Manzano M, Diaz-Castro J, López-Aliaga I, Rueda R, López-Pedrosa JM. Maternal dietary supplementation with oligofructose-enriched inulin in gestating/lactating rats preserves maternal bone and improves bone microarchitecture in their offspring. PloS one. 2016;11(4):e0154120.

6. Thum C, Cookson A, Otter D, McNabb W, Roy CN. In Vitro Fermentation of Caprine Milk Oligosaccharides by Bifidobacteria Isolated from Breast-Fed Infants. Gut Microbes. 2015;6(6).

7. Oliveira DL, Costabile A, Wilbey RA, Grandison AS, Duarte LC, Roseiro LB. In vitro evaluation of the fermentation properties and potential prebiotic activity of caprine cheese whey oligosaccharides in batch culture systems. Biofactors. 2012;6(38):440-9.

8. Thum C, McNabb WC, Young W, Cookson AL, Roy NC. Prenatal caprine milk oligosaccharide consumption affects the development of mice offspring. Molecular nutrition \& food research. 2016;60(9):2076-85.

9. Serino M, Luche E, Gres S, Baylac A, Bergé M, Cenac C, et al. Metabolic adaptation to a high-fat diet is associated with a change in the gut microbiota. Gut. 2012;61(4):543-53.

10. Lam YY, Ha CW, Campbell CR, Mitchell AJ, Dinudom A, Oscarsson J, et al. Increased gut permeability and microbiota change associate with mesenteric fat inflammation and metabolic dysfunction in diet-induced obese mice. PLoS One. 2012;7(3):e34233.

11. Geurts L, Lazarevic V, Derrien M, Everard A, Van Roye M, Knauf C, et al. Altered gut microbiota and endocannabinoid system tone in obese and diabetic leptin-resistant mice: impact on apelin regulation in adipose tissue. Frontiers in microbiology. 2011;2.

12. Parnell JA, Reimer RA. Effect of prebiotic fibre supplementation on hepatic gene expression and serum lipids: a dose-response study in JCR: LA-cp rats. Br J Nutr. 2010;103(11):1577-84.

13. Nguyen P, Leray V, Diez M, Serisier S, Bloc'h JL, Siliart B, et al. Liver lipid metabolism. Journal of Animal Physiology and Animal Nutrition. 2008;92(3):272-83. 
14. Sharma S, Puri S. Prebiotics and lipid metabolism: a review. Altern Ther Health Med. 2015;21(suppl 3):34-42.

15. Thum C, Cookson A, McNabb W, Roy CN, Otter D. Composition and enrichment of caprine milk oligosaccharides from New Zealand Saneen goat cheese whey. Journal of Food Composition and Analysis. 2015;42:30-7.

16. Wheeler DL, Barrett T, Benson DA, Bryant SH, Canese K, Church DM, et al. Database resources of the national center for biotechnology information. Nucleic Acids Res. 2005;33(suppl_1):D39-D45.

17. Team C. R: A language and environment for statistical computing. R Foundation for Statistical Computing. Vienna, Austria. 2016 [Available from: https://www.R-project.org/.

18. Ritchie ME, Phipson B, Wu D, Hu Y, Law CW, Shi W, et al. limma powers differential expression analyses for RNA-sequencing and microarray studies. Nucleic Acids Res. 2015;43(7):e47-e.

19. Montojo J, Zuberi K, Rodriguez H, Kazi F, Wright G, Donaldson SL, et al. GeneMANIA Cytoscape plugin: fast gene function predictions on the desktop. Bioinformatics. 2010;26(22):2927-8.

20. Shannon P, Markiel A, Ozier O, Baliga NS, Wang JT, Ramage D, et al. Cytoscape: a software environment for integrated models of biomolecular interaction networks. Genome Res. 2003;13(11):2498-504.

21. Ligtenberg W. reactome.db: A set of annotation maps for reactome. R package version 1.58.0 ed2016.

22. Winder Wa, Hardie D. AMP-activated protein kinase, a metabolic master switch: possible roles in type 2 diabetes. American Journal of Physiology-Endocrinology And Metabolism. 1999;277(1):E1-E10.

23. Zhang $\mathrm{Y}$, Guo $\mathrm{H}$, Chen X. Lipocalin 2 is an important regulator of lipid metabolism and energy utilization. Federation of American Societies for Experimental Biology; 2011.

24. Lambertz J, Berger T, Mak TW, van Helden J, Weiskirchen R. Lipocalin-2 in fructose-induced fatty liver disease. Frontiers in physiology. 2017;8:964.

25. Smith JL, Lear SR, Forte TM, Ko W, Massimi M, Erickson SK. Effect of pregnancy and lactation on lipoprotein and cholesterol metabolism in the rat. J Lipid Res. 1998;39(11):2237-49.

26. Herzig S, Hedrick S, Morantte I, Koo S-H, Galimi F, Montminy M. CREB controls hepatic lipid metabolism through nuclear hormone receptor PPAR-y. Nature. 2003;426(6963):190.

27. Callis J. The ubiquitination machinery of the ubiquitin system. The Arabidopsis book/American Society of Plant Biologists. 2014;12.

28. Li J, Lu D, Dou H, Liu H, Weaver K, Wang W, et al. Desumoylase SENP6 maintains osteochondroprogenitor homeostasis by suppressing the p53 pathway. Nature communications. 2018;9(1):143.

29. Nagarajan SR, Brandon AE, McKenna JA, Shtein HC, Nguyen TQ, Suryana E, et al. Insulin and dietinduced changes in the ubiquitin-modified proteome of rat liver. PloS one. 2017;12(3):e0174431.

30. Guillén N, Navarro MA, Arnal C, Noone E, Arbonés-Mainar JM, Acín S, et al. Microarray analysis of hepatic gene expression identifies new genes involved in steatotic liver. Physiological Genomics. 
2009;37(3):187-98.

31. Nasiri M, Nikolaou N, Parajes S, Krone NP, Valsamakis G, Mastorakos G, et al. 5a-reductase type 2 regulates glucocorticoid action and metabolic phenotype in human hepatocytes. Endocrinology. 2015;156(8):2863-71.

32. Glick D, Zhang W, Beaton $M$, Marsboom G, Gruber $M$, Simon MC, et al. BNip3 regulates mitochondrial function and lipid metabolism in the liver. Mol Cell Biol. 2012:MCB. 00167-12.

33. Anderson KE, Kappas A. Dietary regulation of cytochrome P450. Annu Rev Nutr. 1991;11(1):141-67.

34. Cherala G, Shapiro BH. Effect of perinatal low protein diets on the ontogeny of select hepatic cytochrome p450 enzymes and cytochrome p450 reductase in the rat. Drug metabolism and disposition. 2007.

35. Renaud HJ, Cui JY, Lu H, Klaassen CD. Effect of Diet on Expression of Genes Involved in Lipid Metabolism, Oxidative Stress, and Inflammation in Mouse Liver-Insights into Mechanisms of Hepatic Steatosis. PloS one. 2014;9(2):e88584.

36. Spector AA, Fang X, Snyder GD, Weintraub NL. Epoxyeicosatrienoic acids (EETs): metabolism and biochemical function. Prog Lipid Res. 2004;43(1):55-90.

37. Baiocchini A, Montaldo C, Conigliaro A, Grimaldi A, Correani V, Mura F, et al. Extracellular matrix molecular remodeling in human liver fibrosis evolution. PLoS One. 2016;11(3):e0151736.

38. lozzo RV, Schaefer L. Proteoglycan form and function: a comprehensive nomenclature of proteoglycans. Matrix Biol. 2015;42:11-55.

39. Shuster A, Patlas M, Pinthus J, Mourtzakis M. The clinical importance of visceral adiposity: a critical review of methods for visceral adipose tissue analysis. The British journal of radiology. 2012;85(1009):1-10.

40. Montgomery M, Hallahan N, Brown S, Liu M, Mitchell T, Cooney G, et al. Mouse strain-dependent variation in obesity and glucose homeostasis in response to high-fat feeding. Diabetologia. 2013;56(5):1129-39.

\section{Tables}

Table 1 Composition of diets and caprine milk oligosaccharide enriched fraction. 


\begin{tabular}{lllll}
\hline & Control diet (AIN76A) & GOS diet & CMO diet \\
\cline { 2 - 5 } Ingredients a & grams & grams & grams \\
\hline Casein & 200 & 200 & 200 \\
DL-Methionine & 3 & 3 & 3 \\
\hline Corn Starch & 150 & 500 & 500 \\
\hline Maltodextrin & 0 & 150 & 150 \\
\hline Sucrose b & 500 & 0 & 0 \\
\hline Cellulose, BW200 & 50 & 50 & 50 \\
\hline Corn oil & 50 & 50 & 50 \\
\hline Mineral mix S10001 & 35 & 35 & 35 \\
\hline Vitamin Mix V10001 & 10 & 10 & 10 \\
\hline Choline Bitartrate & 2 & 2 & 2 \\
\hline Components & grams & & grams & grams \\
\hline Protein & & 10 & 0.014 \\
\hline Gos & & 3.34 & 3.34 \\
\hline Lactose & & 10 & 10 \\
\hline Glucose & & 6.68 & 6.68 \\
\hline Galactose & & & 11 \\
\hline Oligosaccharide c & & & 0.028 \\
\hline Calcium & & & 0.014 \\
\hline Magnesium & & & 0.377 \\
\hline Potassium & Sodium & & 0.21 \\
\hline lodine & Selenium & & 0.0001 \\
\hline Total & & & 1033.6 \\
\hline
\end{tabular}

1. a) All ingredients of the AIN-76A, GOS and CMO diet (except CMOF, sourced from New Zealand, and GOS, sourced from Yakult, Japan), were supplied by Research Diets. b) The sucrose concentration was adjusted in the CMO and GOS diets to balance the energy and nutritional content of the AIN-76A diet. ${ }^{c)}$ Caprine milk oligosaccharides and their abundance: (13\%) 3'- and/or 6'-galactosyl-lactose, (27\%) 3'- and/or 6'-sialyllactose, (32\%) 6'-glycolyl-neuraminyl-lactose, (9\%) lacto-N-hexaose, (11\%) disialyl-N-lactose, (8\%) 6'-NacetyL-glucosaminyl-lactose. Diet composition as previous described (8).

Table 2 Genes differently expressed in dams fed CMO compared to control diet. 


\begin{tabular}{|c|c|c|c|c|c|}
\hline Pathway & GOID & Gene ID & $\begin{array}{l}\text { Gene } \\
\text { name }\end{array}$ & $\begin{array}{l}\text { Fold change } \\
\text { in gene } \\
\text { expression }\end{array}$ & $F D R$ \\
\hline \multirow[t]{4}{*}{ Regulation of lipid metabolism } & GO:0010878 & NM_008491 & Lcn2 & -7.11 & 0.001 \\
\hline & & NM_016781 & Prkag1 & -1.5 & 0.04 \\
\hline & GO:0010885 & NM_009693 & Apob & 2.23 & 0.03 \\
\hline & & NM_009952 & Creb1 & 1.62 & 0.01 \\
\hline \multirow{8}{*}{$\begin{array}{l}\text { Ubiquitin-protein ligase and small ubiquitin-like } \\
\text { modifier (SUMO) ligase activity }\end{array}$} & GO:0004842 & NM_009459 & Ube2h & 1.7 & 0.02 \\
\hline & \multirow{2}{*}{ GO:0019789 } & AK020443 & Ube2d3 & 1.7 & 0.04 \\
\hline & & NM_010064 & Ube2e3 & 1.7 & 0.02 \\
\hline & GO:0016881 & NM_026689 & Mul1 & -1.53 & 0.009 \\
\hline & \multirow{4}{*}{ GO:0019787 } & NM_025739 & Rnf220 & 1.58 & 0.03 \\
\hline & & NM_033604 & Rnf111 & 2.3 & 0.04 \\
\hline & & NM_146003 & Senp6 & 1.7 & 0.001 \\
\hline & & NM_201373 & Trim56 & 1.7 & 0.02 \\
\hline
\end{tabular}

GO ID: gene ontology identification number; FDR: false discovery rate.

Table 3 Genes differently expressed in pups at weaning from dams fed CMO compared to control diet $(\mathrm{n}=4$ per treatment per age group).

\begin{tabular}{|c|c|c|c|c|c|}
\hline Pathway & GOID & Gene ID & $\begin{array}{l}\text { Gene } \\
\text { name }\end{array}$ & $\begin{array}{c}\text { Fold } \\
\text { change in } \\
\text { gene } \\
\text { expression }\end{array}$ & $F D R$ \\
\hline \multirow[t]{2}{*}{$\begin{array}{l}\text { Regulation of mitochondrial membrane } \\
\text { permeability involved in apoptotic process }\end{array}$} & $\begin{array}{l}\text { GO:0097345 } \\
\text { GO:1902110 }\end{array}$ & NM_009760 & Bnip3 & -1.8 & 0.02 \\
\hline & $\begin{array}{l}G O: 1902686 \\
\text { GO:0035794 } \\
\text { GO:1902108 }\end{array}$ & NM_133234 & $B b c 3$ & 2.63 & 0.02 \\
\hline \multirow[t]{5}{*}{ Cytochrome $P 450$ activity } & GO:0004497 & NM_009993 & Cyp1a2 & 3.45 & 0.02 \\
\hline & & NM_206537 & Сур2с54 & 2.94 & 0.04 \\
\hline & & $N M \_001001446$ & Сур2c44 & 3.11 & 0.04 \\
\hline & & NM_007825 & Сур7b1 & 3.38 & 0.04 \\
\hline & & NM_145434 & Nr1d1 & 2.09 & 0.008 \\
\hline \multirow[t]{2}{*}{ Steroid metabolism } & GO:0016229 & NM_008295 & Hsd3b5 & 3.97 & 0.04 \\
\hline & & NM_175283 & Srd5a1 & 3.03 & 0.04 \\
\hline
\end{tabular}

GO ID: gene ontology identification number; FDR: false discovery rate

Table 4 Genes differentially expressed in pups 30 days after weaning from dams fed $\mathrm{CMO}$ compared to pups from dams fed the control diet ( $n=4$ per treatment per age group). 


\begin{tabular}{llcll}
\hline Gene ID & Gene name & Fold change in gene expression & FDR & Description \\
\hline NM_001039562 & Ankrd37 & 2.26 & 0.0005 & Ankyrin repeat domain 37 \\
NM_008871 & Serpine1 & 2.31 & 0.005 & Serine peptidase inhibitor. \\
NM_029568 & Mfap4 & 1.90 & 0.02 & Microfibrillar-associated protein 4 \\
NM_011067 & Per3 & 1.71 & 0.02 & Period homolog 3 \\
NM_008597 & Mgp & 3.09 & 0.02 & Matrix Gla protein \\
NM_018874 & Pnliprp1 & 2.42 & 0.03 & Pancreatic lipase related protein 1 \\
NM_028004 & Ttn & 5.46 & 0.04 & Transcript variant N2-A \\
\hline
\end{tabular}

Table 5 GSEA pathway analysis of genes significantly changed in the liver of pups 30 days after weaning from dams fed $\mathrm{CMO}$ diet ( $\mathrm{n}=4$ per treatment per age group).

\begin{tabular}{lcccc}
\hline \multicolumn{1}{c}{ Pathway } & $\begin{array}{c}\text { Number of } \\
\text { Genes }\end{array}$ & $\begin{array}{c}\text { Downregulated } \\
(\%)\end{array}$ & $\begin{array}{c}\text { Upregulated } \\
(\%)\end{array}$ & $\begin{array}{c}P \text { - } \\
\text { value }\end{array}$ \\
\hline $\begin{array}{l}\text { Synthesis of epoxy (EET) and dihydroxyeicosatrienoic } \\
\text { acids (DHET) }\end{array}$ & 27 & 0 & 25 & 0.05 \\
$\begin{array}{l}\text { Assembly of collagen fibrils and other multimeric } \\
\text { structures }\end{array}$ & 54 & 11 & 5 & 0.02 \\
Collagen degradation & & & & \\
Collagen biosynthesis and modifying enzymes & 92 & 6 & 1 & 0.03 \\
Collagen formation & 94 & 6 & 3 & 0.03 \\
Extracellular matrix proteoglycans & 100 & 7 & 3 & 0.04 \\
& 117 & 6 & 0 & 0.02 \\
\hline
\end{tabular}

\section{Figures}

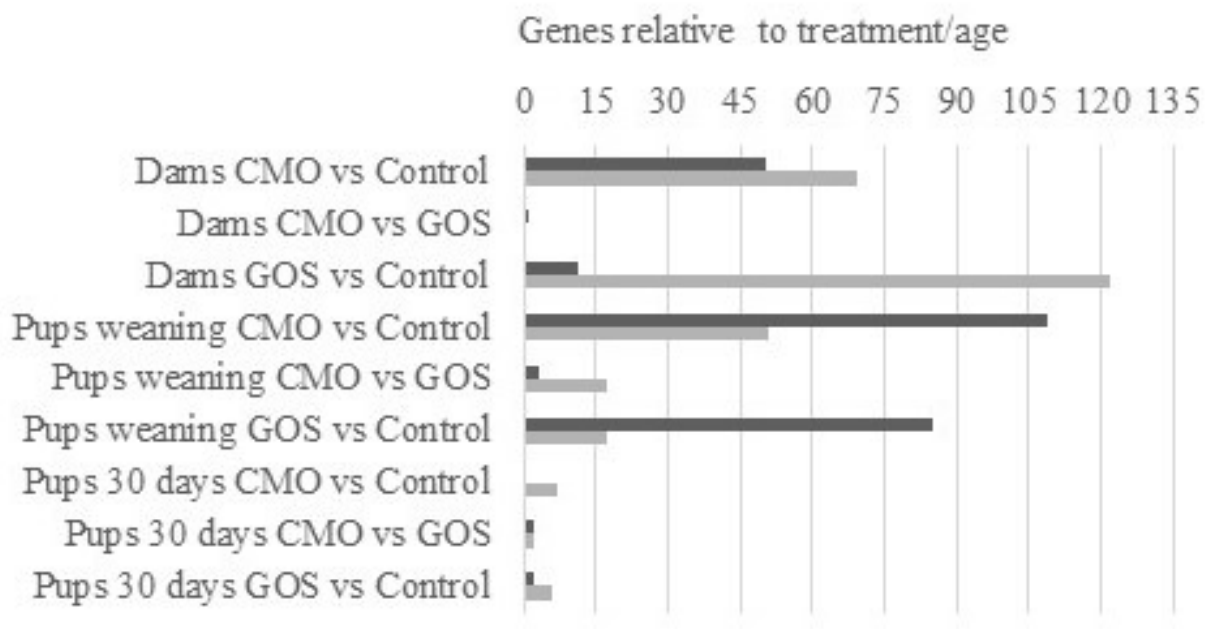

Decreased Increased

Figure 1 
Number of genes with a significant change in expression by each treatment/age $(n=4$ per treatment per age group).

\section{Supplementary Files}

This is a list of supplementary files associated with this preprint. Click to download.

- SupplementarymaterialThumetal.docx 